\title{
EFEITO DA CONCENTRAÇÃO DE SAIS E FITORREGULADORES NA INDUÇÃO DE CALOS EM CARQUEJA
}

\author{
FABIANO GUIMARÃES SILVA ${ }^{1}$ \\ JOSÉ EDUARDO BRASIL PEREIRA PINTO ${ }^{2}$ \\ JULIANA DE FÁTIMA SALES ${ }^{3}$ \\ SHEYLA DE PAULA DIVINO ${ }^{4}$ \\ SUZAN KELY VILELA BERTOLUCCI ${ }^{5}$
}

\begin{abstract}
RESUMO - Realizou-se este trabalho com o objetivo de estudar condições nutricionais e hormonais para maximizar a produção de calos friáveis de carqueja [Baccharis trimera (Less.) DC]. Foi verificado que a iniciação de calo é dependente de fitorreguladores e

da concentração do meio. A melhor indução de calo ocorreu em meio MS contendo 50\% da concentração de sais, inositol e vitaminas, suplementado com 15,0 $\mu \mathrm{M}$ ANA. Proliferação de brotos foi obtida pelo uso de TDZ.
\end{abstract}

TERMOS PARA INDEXAÇÃO: Baccharis trimera, planta medicinal, auxinas, citocininas.

\section{CALLUS INDUCTION IN “CARQUEJA” AS AFFECTED BY SALT CONCENTRATIONS AND GROWTH REGULATORS}

\begin{abstract}
The influence of various growth regulators and medium concentrations, in different quantities, on the in vitro callus induction of carqueja [Baccharis trimera (Less.) DC.] was evaluated. It was found that the callus initiation was dependent on both, the growth regulator and
\end{abstract}

medium concentration. The highest callus induction and development were obtained by using $15.0 \mu \mathrm{M} 1$ napthaleneacetic acid (NAA) as growth regulators and half strength of salts, vitamins, and myo-inositol of Murashige and Skoog medium. In vitro shoot proliferation was obtained by using thidiazuron.

INDEX TERMS: Baccharis trimera, medicinal plant, auxin, cytokinin.

\section{INTRODUÇÃO}

A carqueja (Baccharis trimera Less.) DC. é largamente utilizada na medicina popular na forma de infusão, em razão de suas propriedades antiinflamatórias, cicatrizantes e digestivas (Pedrazzi et al., 1997). Estudos realizados por Avancini et al. (2000) confirmaram a atividade antimicrobiana in vitro do decocto de $B$. trimera.

Um considerável esforço tem sido feito com o intuito de produzir produtos fitoterápicos a partir de cultura de células ou tecidos da planta. No entanto, são raros os processos economicamente viáveis devido à necessidade de otimização dos compostos ativos que de- pendem, em última instância, do entendimento dos mecanismos genéticos, fisiológicos e morfológicos de controle da biogênese e acúmulo dos compostos bioativos (França, 1999). Além de melhoramento de linhagem, métodos de seleção de linhagens de alta produção, otimização do meio podem levar a um incremento na produção de princípios ativos. O principal problema encontrado na produção de princípios ativos com a utilização de técnicas biotecnológicas é a falta de conhecimento básico das rotas biossintéticas e dos mecanismos responsáveis pela produção dos princípios ativos, ficando a produtividade de princípios ativos limitada pela falta de precussores específicos (Dornenburg \& Knorr, 1995).

\footnotetext{
1. Licenciatura em Ciências Agrícolas, M.Sc., Doutorando Departamento de Agricultura da UNIVERSIDADE FEDERAL DE LAVRAS/UFLA, Caixa Postal 37 - 37200-000 - Lavras, MG. fguimaraess@zipmail.com.br

2. Engenheiro Agrônomo, Ph.D., Professor Titular do Departamento de Agricultura/UFLA.

3. Bióloga, M.Sc.

4. Discente de graduação.

5. Farmacêutica, M.Sc., Professora Assistente do Departamento de Agricultura/UFLA.
} 
Quando o objetivo for a produção de princípios ativos in vitro, a cultura de suspensão de células é mais promissoras. Entretanto, há necessidade de estabelecimento de protocolo eficiente para indução de calos. Assim, com o presente trabalho objetivou-se estudar condições nutricionais e hormonais para maximizar a produção de calos friáveis, visando a futuro estudo de produção de princípios ativos dessa espécie, mediante a cultura de calos e suspensão celular.

\section{MATERIAL E MÉTODOS}

Como material vegetal, utilizaram-se ápices caulinares de aproximadamente $0,5 \mathrm{~cm}$ de comprimento de carqueja [Baccharis trimera (Less.) DC.] oriundos de planta-matriz localizada no Horto de Plantas Medicinais da Universidade Federal de Lavras, Minas Gerais. A coleta foi realizada nos meses de setembro e dezembro do ano de 2000, respectivamente primeiro e segundo experimento. A exsicata do material vegetal encontra-se registrada no Herbário do Departamento de Biologia/UFLA, sob o número 169933.

No primeiro experimento, os meios de cultura utilizados foram MS-100, concentração original dos sais Murashige \& Skoog (1962), e MS-50, metade da concentração original dos sais MS, de vitaminas e de inositol, suplementado com 30 g.L. ${ }^{-1}$ de sacarose, 6 g.L. ${ }^{-1}$ de ágar e $\mathrm{pH} 5,7$. Os fitorreguladores utilizados foram as citocininas benzilaminopurina (BAP) e cinetina (CIN), e a auxina ácido naftalenoacético (ANA), nas concentrações de 2,5 e 10,0 $\mu \mathrm{M}$. No segundo experimento, o meio de cultura utilizado foi o MS-50, suplementado com 35 balanços de fitorreguladores, incluindo as citocininas CIN e tidiazuron (TDZ), nas concentrações de 1,25 e 2,50 $\mu \mathrm{M}$, e as auxinas ANA e ácido 2,4-diclorofenoxiacético (2,4-D), nas concentrações de 5,0, 10,0 e 15,0 $\mu \mathrm{M}$.

Foram realizadas pulverizações nas plantasmatrizes com Benomil ${ }^{\circledR}$ 0,2\%, 48 e 24 horas antes da coleta dos explantes. Após a coleta, os ápices foram lavados em água corrente por 15 minutos, seguidos por 30 segundos em etanol (70\%) e, por último, 20 minutos em água sanitária Q-Boa Bactericida ${ }^{\circledR}(30 \%)$. Em capela de fluxo laminar, foram realizados 4 banhos em água destilada autoclavada. Após a lavagem e limpeza do material vegetal (toalete), os explantes foram excisados e inoculados em tubos de ensaio $(25 \times 150 \mathrm{~mm})$ contendo $10 \mathrm{~mL}$ de meio de cultura. No segundo experimento, a metodologia foi idêntica, exceto o tempo de permanência em Q-Boa Bactericida ${ }^{\circledR}$, que foi reduzido para 15 minutos. Após inoculação, os ápices foram incubados em sala de crescimento com fotoperíodo de 16 horas, irradiância de $15 \mu \mathrm{mol} . \mathrm{m}^{-2} . \mathrm{s}^{-1}$ e temperatura de $25 \pm 2^{\circ} \mathrm{C}$. No primeiro experimento, ao final de 60 dias de cultivo, foi determinada a biomassa fresca. No segundo experimento, ao final de 45 dias, foram avaliados a porcentagem de explantes vivos, brotações formadas e calos, bem como a biomassa fresca.

$\mathrm{O}$ delineamento experimental no primeiro experimento foi inteiramente casualizado (DIC), disposto em esquema fatorial $(2 \times 15)$, sendo duas concentrações dos sais MS e 15 balanços de fitorreguladores. Cada parcela foi constituída por 5 tubos e cada tratamento foi constituído por 25 tubos. No segundo experimento, o delineamento experimental foi inteiramente casualizado (DIC), com 35 balanços de fitorreguladores, cada um constituído por 25 tubos. Cada parcela foi constituída por 5 tubos.

\section{RESULTADOS E DISCUSSÃO}

No primeiro experimento, pela análise da Tabela 1 verifica-se que não ocorreu sobrevivência dos ápices em ausência de fitorreguladores ou quando se utilizou CIN somente. A adição de ANA foi fundamental para a otimização da indução e crescimento dos calos, nos quais seu uso individualizado apresentou produção de biomassa satisfatória. A inclusão de BAP e CIN apresentou efeito positivo somente em conjunto com ANA. Resultados semelhantes foram verificados por Nin et al., (1996), em que o BAP adicionado individualizado ao meio, nas concentrações de 0,88 e $2,22 \mu \mathrm{M}$, mostrou-se ineficiente em induzir desdiferenciação e crescimento de calos em Artemisia absinthium L. (Asteraceae). Análise das médias sobre as concentrações do meio de cultura revelaram que maiores crescimentos de calos ocorreram em presença de $10,0 \mu \mathrm{M}$ de ANA individualizado, bem como adição conjunta de $2,5 \mu \mathrm{M}$ de BAP ou CIN e 10,0 $\mu \mathrm{M}$ de CIN. Relações citocininas/auxinas 2,5/2,5 $\mu \mathrm{M} ; 10,0 / 2,5 \mu \mathrm{M}$ e $10,0 / 10,0$ BAP/ANA apresentaram crescimentos intermediários. Menores induções e crescimentos de calos foram obtidos em ausência de fitorreguladores ou quando foram utilizadas as citocininas BAP e CIN individualizadas.

Quando a concentração dos sais, vitaminas e inositol do meio de cultura foram reduzidos em $50 \%$ (MS-50), ocorreu maior crescimento de calos, comparados ao meio MS-100. Os maiores acúmulos de biomassa foram observados em meio MS-50, suplementado, respectivamente, com 10,0 $\mu \mathrm{M}$ de ANA individua- 
lizado ou em conjunto com 2,5 de CIN; 2,5 $\mu \mathrm{M}$ de ANA com 2,5 $\mu \mathrm{M}$ de BAP ou CIN. Em meio MS-100, acúmulo de biomassa maior que 4,00 $\mathrm{g}$ ocorreu apenas nos meios suplementados com 10,0 $\mu \mathrm{M}$ de ANA com $2,5 \mu \mathrm{M}$ de BAP ou CIN. Com relação à maior eficiência do meio de cultura MS-50, esses resultados estão de acordo com os obtidos para Hydrocotyle asiatica L., que apresentou melhores resultados na indução de calos, em meio com metade da concentração de sais MS (Josekutty, 1998).

Uma visão geral do efeito entre os diferentes fitorreguladores no segundo experimento pode ver visualizada na Figura 1. Como ocorrido no experimento anterior, em todos os tratamentos que induziram calos, esses apresentaram uma consistência friável. A ocorrência de calos friáveis, segundo Cid (1998), pode ser devida a relações mais elevadas auxina/citocinina, e de acordo com França (1999), pelo fato de os calos terem sido cultivados em presença de luz, conferindo, geralmente, maior friabilidade que os cultivados em ausência de luz.

Novamente, em ausência de fitorreguladores, ou apenas CIN nas concentrações avaliadas, o número de explantes viáveis foi nulo ou desprezível (tabela 2). Para que seja alcançada uma maior porcentagem de so- brevivência de explantes, ficou clara a importância da auxina ANA individualizada ou em conjunto com as citocininas CIN ou TDZ. Nesses meios, ocorreu uma maior sobrevivência dos explantes nas concentrações de ANA avaliada, exceto em meio suplementado com 15,0 $\mu \mathrm{M}$ de 2,4-D com 1,25 $\mu \mathrm{M}$ de TDZ, que apresentou sobrevivência de explantes comparável aos meios suplementados com ANA. A sobrevivência intermediária dos explantes foi alcançada em meios suplementados com auxina 2,4D individualizada ou em combinação com CIN ou TDZ $(1,25$ e $2,50 \mu \mathrm{M})$ e $1,25 \mu \mathrm{M}$ de TDZ. A ausência de sobrevivência em explantes cultivados em meio desprovido de fitorreguladores provavelmente foi devida ao nível endógeno de hormônios insuficientes para induzir ou manter a divisão celular. Resultados semelhantes foram observados por vários autores para outras espécies de plantas, como Ambrosia tenuifolia Spreng. (Goleniowski et al., 1992), Artemisia absinthium (Asteraceae) (Nin et al., 1996) e para quatro espécies do gênero Baccharis (B. coridifolia DC., B. halimifolia L., B. megapotamica Spreng. e B. neglecta Britton \& A. Brown), nas quais praticamente não se obtiveram sobrevivência dos explantes e formação de calo em ausência de fitorreguladores (Kuti \& Jarvis, 1992).

TABELA 1 - Biomassa fresca de calos de explantes apicais de B. trimera aos 60 dias de cultivo em meio MS-50 e MS-100 e diferentes combinações e concentrações de fitorreguladores.

\begin{tabular}{cccccc}
\hline \multicolumn{2}{c}{ Fitorreguladores $(\boldsymbol{\mu M})$} & \multicolumn{3}{c}{ Biomassa fresca $(\mathbf{g})$} \\
\hline BAP & CIN & ANA & MS-50 & MS-100 & Média \\
\hline- & - & - & --- & --- & --- \\
2,5 & - & - & $0,089 \mathrm{Fa}^{\mathrm{Z}}$ & $0,15 \mathrm{Da}$ & $0,12 \mathrm{D}$ \\
10,0 & - & - & $0,61 \mathrm{EFa}$ & $0,14 \mathrm{Da}$ & $0,38 \mathrm{D}$ \\
- & 2,5 & - & --- & --- & --- \\
- & 10,0 & - & --- & -- & --- \\
- & - & 2,5 & $2,04 \mathrm{DEa}$ & $0,28 \mathrm{Db}$ & $1,16 \mathrm{D}$ \\
- & - & 10,0 & $5,04 \mathrm{ABa}$ & $3,84 \mathrm{ABb}$ & $4,44 \mathrm{AB}$ \\
2,5 & - & 2,5 & $4,35 \mathrm{ABCa}$ & $2,48 \mathrm{ABCb}$ & $3,42 \mathrm{BC}$ \\
- & 2,5 & 2,5 & $3,99 \mathrm{ABCa}$ & $1,71 \mathrm{CDb}$ & $2,85 \mathrm{C}$ \\
2,5 & - & 10,0 & $3,35 \mathrm{BCDa}$ & $4,20 \mathrm{Aa}$ & $3,78 \mathrm{ABC}$ \\
- & 2,5 & 10,0 & $5,48 \mathrm{Aa}$ & $4,10 \mathrm{Ab}$ & $4,79 \mathrm{~A}$ \\
10,0 & - & 2,5 & $3,29 \mathrm{BCDa}$ & $2,78 \mathrm{ABCa}$ & $3,04 \mathrm{C}$ \\
- & 10,0 & 2,5 & $3,43 \mathrm{BCDa}$ & $2,00 \mathrm{BCDb}$ & $2,71 \mathrm{C}$ \\
10,0 & - & 10,0 & $2,83 \mathrm{CDa}$ & $2,64 \mathrm{ABCa}$ & $2,73 \mathrm{C}$ \\
- & 10,0 & 10,0 & $3,78 \mathrm{ABCDa}$ & $3,55 \mathrm{ABCa}$ & $3,66 \mathrm{ABC}$ \\
& Média & & $2,56 \mathrm{~A}$ & $1,87 \mathrm{~B}$ & 2,22 \\
\hline
\end{tabular}

${ }^{\mathrm{z}}$ Médias seguidas pela mesma letra maiúscula entre fitorreguladores e minúscula entre concentrações dos sais MS não diferem entre si pelo teste de Tukey a 5\% de probabilidade. 


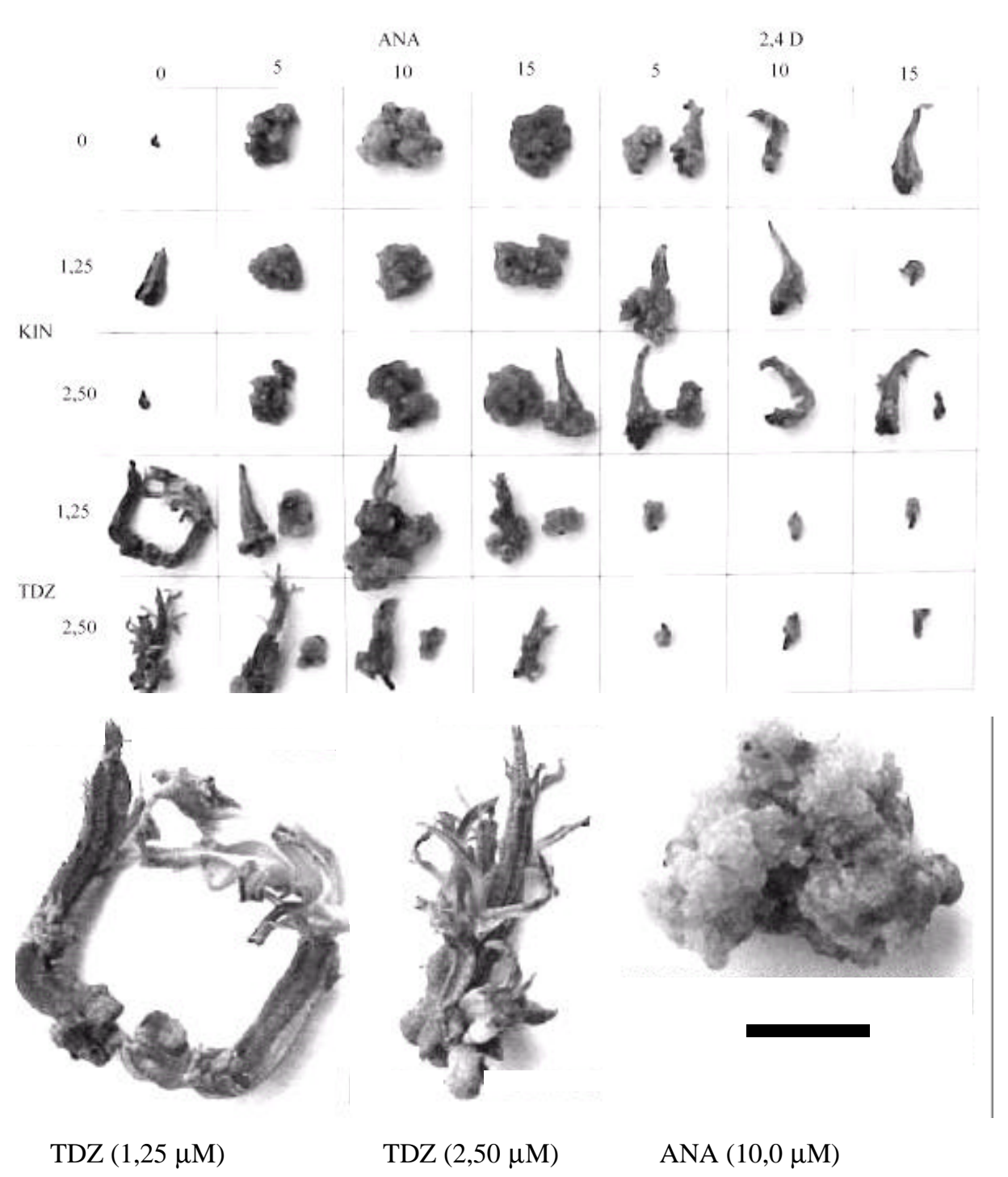

FIGURA 1 - Efeitos do balanço de fitorreguladores na morfogênese de B. trimera, cultivada em meio MS-50, evidenciando a indução de brotos com TDZ e calos com ANA, aos 45 dias de cultivo (Barra $=1 \mathrm{~cm})$.

A maior indução e crescimento de calos ocorreu em meio suplementado com $15,0 \mu \mathrm{M}$ de ANA individualizado, ou nas concentrações de 10,0 e 15,0 $\mu \mathrm{M}$ em combinação com 1,25 ou 2,50 $\mu \mathrm{M}$ de CIN. Dentre as auxinas, ANA foi mais eficiente na indução e crescimento de calos quando comparada ao 2,4-D utilizado individualizado, em conjunto com CIN ou TDZ em qualquer concentração avaliada. A presença de TDZ reduziu significativamente a indução e crescimento de calos. A indução de calos é provocada por injúrias no tecido e/ou por indução química, e o genótipo pode res- ponder às duas classes de fitorreguladores, citocinina e auxina, e às suas diferentes combinações. A carqueja (B. trimera) respondeu mais efetivamente à presença de fitorreguladores em duas classes, auxina e auxina com citocinina. Entretanto, os explantes mostraram maior indução com auxina individualizada no meio de cultura. Quanto à suficiência da adição individual de ANA na indução e crescimento de calo, demonstrou-se que a espécie em estudo não se comportou como a maioria das plantas dicotiledôneas, nas quais uma citocinina é quase sempre adicionada ao meio com auxina (George, 
1993). Esse fato foi interessante, pois de acordo com os objetivos iniciais, futuramente pretende-se desenvolver estudos com culturas de células, e auxinas promovem a dispersão celular em culturas de suspensão, enquanto as citocininas geralmente causam a agregação das células.

TABELA 2 - Porcentagem de explantes viáveis, brotações, indução e biomassa fresca de calos em explantes apicais de $B$. trimera, aos 45 dias de cultivo em meio MS-50.

\begin{tabular}{|c|c|c|c|c|c|}
\hline \multicolumn{2}{|c|}{ Fitorreguladores $(\mu \mathrm{M})$} & \multirow{2}{*}{$\begin{array}{c}\text { Explantes vivos } \\
(\%)\end{array}$} & \multirow{2}{*}{$\begin{array}{c}\text { Brotações } \\
(\%)\end{array}$} & \multirow{2}{*}{$\begin{array}{c}\text { Indução de calos } \\
(\%)\end{array}$} & \multirow{2}{*}{$\begin{array}{c}\text { Biomassa fresca } \\
\text { (g) }\end{array}$} \\
\hline Auxinas & Citocininas & & & & \\
\hline 0 & 0 & $0,00 \mathrm{D}^{\mathrm{Z}}$ & $0,00 \mathrm{C}$ & $0,00 \mathrm{~F}$ & $0,00 \mathrm{~F}$ \\
\hline ANA $(5,0)$ & 0 & $100,00 \mathrm{~A}$ & $36,00 \mathrm{~B}$ & $55,00 \mathrm{~B}$ & $0,30 \mathrm{D}$ \\
\hline ANA $(10,0)$ & 0 & $90,79 \mathrm{~A}$ & $31,72 \mathrm{~B}$ & $65,00 \mathrm{~B}$ & $0,50 \mathrm{~B}$ \\
\hline ANA $(15,0)$ & 0 & $96,00 \mathrm{~A}$ & $16,00 \mathrm{C}$ & $92,00 \mathrm{~A}$ & $0,72 \mathrm{~A}$ \\
\hline 2.4-D $(5,0)$ & 0 & $79,16 \mathrm{~B}$ & $26,08 \mathrm{~B}$ & $23,91 \mathrm{D}$ & $0,14 \mathrm{E}$ \\
\hline 2.4-D $(10,0)$ & 0 & $32,00 \mathrm{C}$ & $16,00 \mathrm{C}$ & $3,80 \mathrm{~F}$ & $0,06 \mathrm{~F}$ \\
\hline 2.4-D $(15,0)$ & 0 & $54,16 \mathrm{C}$ & $39,12 \mathrm{~B}$ & $10,25 \mathrm{E}$ & $0,14 \mathrm{E}$ \\
\hline 0 & CIN $(1,25)$ & $4,64 \mathrm{D}$ & $4,48 \mathrm{C}$ & $0,00 \mathrm{~F}$ & $0,00 \mathrm{~F}$ \\
\hline ANA $(5,0)$ & CIN $(1,25)$ & $88,00 \mathrm{~A}$ & $20,00 \mathrm{C}$ & $61,87 \mathrm{~B}$ & $0,42 \mathrm{C}$ \\
\hline ANA $(10,0)$ & CIN $(1,25)$ & $100,00 \mathrm{~A}$ & $28,00 \mathrm{~B}$ & $80,00 \mathrm{~A}$ & $0,64 \mathrm{~A}$ \\
\hline ANA $(15,0)$ & CIN $(1,25)$ & $100,00 \mathrm{~A}$ & $12,00 \mathrm{C}$ & $96,87 \mathrm{~A}$ & $0,81 \mathrm{~A}$ \\
\hline $2,4-\mathrm{D}(5,0)$ & CIN $(1,25)$ & $76,00 \mathrm{~B}$ & $8,00 \mathrm{C}$ & $16,33 \mathrm{E}$ & $0,08 \mathrm{~F}$ \\
\hline $2,4-\mathrm{D}(10,0)$ & CIN $(1,25)$ & $21,68 \mathrm{D}$ & $8,68 \mathrm{C}$ & $6,30 \mathrm{~F}$ & $0,04 \mathrm{~F}$ \\
\hline $2,4-\mathrm{D}(15,0)$ & CIN $(1,25)$ & $32,28 \mathrm{C}$ & $14,24 \mathrm{C}$ & $8,50 \mathrm{E}$ & $0,05 \mathrm{~F}$ \\
\hline 0 & CIN $(2,50)$ & $0,00 \mathrm{D}$ & $0,00 \mathrm{C}$ & $0,00 \mathrm{~F}$ & $0,00 \mathrm{~F}$ \\
\hline ANA $(5,0)$ & CIN $(2,50)$ & $91,28 \mathrm{~A}$ & 39,12 B & $66,81 \mathrm{~B}$ & $0,51 \mathrm{~B}$ \\
\hline ANA $(10,0)$ & CIN $(2,50)$ & $90,79 \mathrm{~A}$ & $18,88 \mathrm{C}$ & $85,00 \mathrm{~A}$ & $0,70 \mathrm{~A}$ \\
\hline ANA $(15,0)$ & CIN $(2,50)$ & $94,39 \mathrm{~A}$ & $31,72 \mathrm{~B}$ & $85,22 \mathrm{~A}$ & $0,68 \mathrm{~A}$ \\
\hline $2,4-\mathrm{D}(5,0)$ & CIN $(2,50)$ & $68,00 \mathrm{~B}$ & $36,00 \mathrm{~B}$ & $15,22 \mathrm{E}$ & $0,15 \mathrm{E}$ \\
\hline $2,4-\mathrm{D}(10,0)$ & CIN $(2,50)$ & $48,00 \mathrm{C}$ & $44,00 \mathrm{~A}$ & $6,42 \mathrm{~F}$ & $0,14 \mathrm{E}$ \\
\hline $2,4-\mathrm{D}(15,0)$ & CIN $(2,50)$ & $36,00 \mathrm{C}$ & $20,80 \mathrm{C}$ & $4,37 \mathrm{~F}$ & $0,07 \mathrm{~F}$ \\
\hline 0 & TDZ $(1,25)$ & $44,00 \mathrm{C}$ & $44,00 \mathrm{~A}$ & $0,00 \mathrm{~F}$ & $0,10 \mathrm{~F}$ \\
\hline ANA $(5,0)$ & TDZ $(1,25)$ & $91,66 \mathrm{~A}$ & $16,66 \mathrm{C}$ & $65,21 \mathrm{~B}$ & $0,26 \mathrm{D}$ \\
\hline ANA $(10,0)$ & $\operatorname{TDZ}(1,25)$ & $83,32 \mathrm{~A}$ & $56,48 \mathrm{~A}$ & $35,22 \mathrm{C}$ & $0,36 \mathrm{C}$ \\
\hline ANA $(15,0)$ & $\operatorname{TDZ}(1,25)$ & $84,00 \mathrm{~A}$ & $28,00 \mathrm{~B}$ & $41,38 \mathrm{C}$ & $0,14 \mathrm{E}$ \\
\hline $2,4-\mathrm{D}(5,0)$ & $\operatorname{TDZ}(1,25)$ & $60,80 \mathrm{~B}$ & $9,08 \mathrm{C}$ & $15,47 \mathrm{E}$ & $0,04 \mathrm{~F}$ \\
\hline $2,4-\mathrm{D}(10,0)$ & TDZ $(1,25)$ & $75,00 \mathrm{~B}$ & $6,23 \mathrm{C}$ & $23,66 \mathrm{D}$ & $0,04 \mathrm{~F}$ \\
\hline $2,4-\mathrm{D}(15,0)$ & $\operatorname{TDZ}(1,25)$ & $80,80 \mathrm{~A}$ & $9,52 \mathrm{C}$ & $13,15 \mathrm{E}$ & $0,04 \mathrm{~F}$ \\
\hline 0 & $\operatorname{TDZ}(2,50)$ & $58,32 \mathrm{~B}$ & $58,32 \mathrm{~A}$ & $0,00 \mathrm{~F}$ & $0,16 \mathrm{E}$ \\
\hline ANA $(5,0)$ & TDZ $(2,50)$ & $76,00 \mathrm{~B}$ & $28,00 \mathrm{~B}$ & $25,65 \mathrm{D}$ & $0,30 \mathrm{D}$ \\
\hline ANA $(10,0)$ & $\operatorname{TDZ}(2,50)$ & $62,48 \mathrm{~B}$ & $20,80 \mathrm{C}$ & $23,94 \mathrm{D}$ & $0,17 \mathrm{E}$ \\
\hline ANA $(15,0)$ & $\operatorname{TDZ}(2,50)$ & $59,08 \mathrm{~B}$ & $4,54 \mathrm{C}$ & $31,90 \mathrm{C}$ & $0,07 \mathrm{~F}$ \\
\hline $2,4-\mathrm{D}(5,0)$ & $\operatorname{TDZ}(2,50)$ & $73,51 \mathrm{~B}$ & $15,92 \mathrm{C}$ & $21,76 \mathrm{D}$ & $0,05 \mathrm{~F}$ \\
\hline $2,4-\mathrm{D}(10,0)$ & TDZ $(2,50)$ & $45,80 \mathrm{C}$ & $16,64 \mathrm{C}$ & $6,40 \mathrm{~F}$ & $0,03 \mathrm{~F}$ \\
\hline $2,4-\mathrm{D}(15,0)$ & $\operatorname{TDZ}(2,50)$ & $29,16 \mathrm{C}$ & $4,16 \mathrm{C}$ & $3,00 \mathrm{~F}$ & $0,01 \mathrm{~F}$ \\
\hline
\end{tabular}

${ }^{\mathrm{Z}}$ Médias seguidas pela mesma letra não diferem entre si pelo teste de Scott Knott a $5 \%$ de probabilidade. 
Neste trabalho ocorreu indução de brotações, que atingiu maiores valores em meios suplementados com TDZ individualizado em ambas as concentrações estudadas, na interação de 1,25 $\mu \mathrm{M}$ deste com 10,0 $\mu \mathrm{M}$ de ANA e 2,50 $\mu \mathrm{M}$ de CIN com 10,0 $\mu \mathrm{M}$ de 2,4-D. Em presença das auxinas ANA ou 2,4-D, ocorreu formação de calos na base dos explantes, o que não é interessante quando o objetivo for a propagação in vitro. Observação semelhante foi realizada para Achillea asplenifolia Vent. (Asteraceae), em que foi verificado que a adição de auxinas ao meio de cultura prejudicou a regeneração de brotos; além disso, a formação de calos e raízes aumentou fortemente (Wawrosch et al., 1994). Em ausência de auxina, não ocorreu indução de calos. A presença de auxina no meio de cultura exerceu grande inibição da formação de parte aérea; em ausência dessa, $100 \%$ dos explantes viáveis apresentaram, no mínimo, início de formação de brotos. O uso individualizado de CIN iniciou o desenvolvimento das brotações, mas por ocasião da avaliação, aos 45 dias de cultura, essas já se apresentavam totalmente escurecidas. $\mathrm{O}$ grau mais elevado de proliferação celular em resposta a elevadas concentrações de citocininas provavelmente decorreu da redução da quantidade de polifenóis livres (Wildi et al., 1998). Resultados positivos do TDZ em induzir e manter o crescimento das brotações, obtidos neste trabalho, sugerem um maior nível endógeno de citocininas purinas, causado pelo suprimento exógeno com TDZ. No entanto, resultado semelhante não foi observado em presença de CIN. Esse melhor desempenho foi provavelmente devido à habituação causada por esse fitorregulador, ou seja, as fenil uréias são bastante capazes de tornar os explantes autotróficos em citocininas, como ocorrido para regeneração de plantas de fumo, expansão de cotilédones de rabanete e crescimento de calos de soja (Thomas \& Katterman, 1986).

\section{CONCLUSÕES}

Em cultura de ápices caulinares de $B$. trimera não ocorreu sobrevivência dos explantes em ausência de suprimento exógeno de fitorreguladores; o meio de cultura com $50 \%$ da concentração dos sais MS, vitaminas e inositol mostrou-se mais eficiente na indução e crescimento de calos; a auxina ANA na concentração de $15,0 \mu \mathrm{M}$ foi a mais indicada para a indução e crescimento de calos friáveis para futuros estudos de produção de princípios ativos. Para a indução de brotações, TDZ individualizado nas concentrações de 1,25 e 2,50 $\mu \mathrm{M}$ foram os tratamentos mais promissores.

\section{REFERÊNCIAS BIBLIOGRÁFICAS}

AVANCINI, C. A. M.; WIEST, J. M.; MUNDSTOCK, E. Atividade bacteriostática do decocto de Baccharis trimera (Less.) D.C.: compositae, carqueja, como desinfetante ou anti-séptico. Arquivo Brasileiro de Medicina Veterinária e Zootecnia, Belo Horizonte, v. 52, n. 3, p. 230-234, 2000.

CID, L. P. B. Suspensão celular. In: TORRES, A. C.; CALDAS, L. S.; BUSO, J. A. Cultura de tecidos e transformação genética de plantas. Brasília: Embrapa Hortaliças, 1998. v. 1, p.331-353.

DORNENBURG, H.; KNORR, D. Strategies for the improvement of secondary metabolite production in plant cell cultures. Enzyme and Microbial Technology, New York, v. 17, n. 8, p. 674-684, Aug. 1995.

FRANÇA, S. de C. Abordagens biotecnológicas para a obtenção de substâncias ativas. In: SIMÕES, C. M. O.; SCHENKEL, E. P.; GOSMANN, G.; MELLO, J. C. P.; MENTZ, L. A.; PETROVICK, P. R. (Orgs.). Farmacognosia da planta ao medicamento. Porto Alegre: UFRGS; Florianópolis: UFSC, 1999. p. 101-121.

GEORGE, E. F. Plant propagation by tissue culture: part 1. The technology. 2. ed. England: Exegetics, $1993.574 \mathrm{p}$.

GOLENIOWSKI, M. E.; SILVA, G. L.; TRIPPI, V. S. Effect of phytohormones on sesquiterpene lactone production in callus culture of Ambrosia tenuifolia. Phytochemistry, New York, v. 31, n. 7, p. 2359-2361, July 1992.

JOSEKUTTY, P. C. Callus culture and micropropagation of Hydrocotyle asiatica [Centella asiatica (L.) Urban], a medicinal plant. Phyton, Buenos Aires, v. 63, v. 1/2, p. 275-278, 1998.

KUTI J. O.; JARVIS B. B. Growth hormone-like activities of macrocyclic trichothecenes in vitro callus induction and growth of four Baccharis species. Journal of Plant Growth Regulation, New York, v. 11, p. 149154, 1992.

MURASHIGE, T.; SKOOG, F. A revised medium for rapid growth and biossays with tobacco tissue cultures. Physiologia Plantarum, Copenhagen, v. 15, n. 3, p. 473-497, 1962. 
NIN, S.; MOROSI, E.; SCHIFF, S.; BENNICI, A. Callus cultures of Artemisia absinthium L.: initiation, growth optimization and organogenesis. Plant Cell, Tissue and Organ Culture, Hague, v. 45, n. 1, p. 67-72, Apr. 1996.

PEDRAZZI, A. H. P.; RODRIGUES, E. R.; ZANARDO-FILHO, A.; FRANCO, J. J. Hematological evaluation of carqueja (Baccharis trimera) infusion. Fitoterapia, Milan, v. 68, n. 1, p. 26-29, 1997.

THOMAS J. C.; KATTERMAN F. R. Cytokinin activity induced by thidiazuron. Plant Physiology, Rockville, v. 81, n. 2, p. 681-683, June 1986.
WAWROSCH, C.; KOPP, B.; KUBELKA, W. In vitro propagation of Achillea asplenifolia Vent. through multiple shoot regeneration. Plant Cell Reports, New York, v. 14, n. 1, p. 161-164, Dec. 1994.

WILDI, E.; SCHAFFNER, K.; BUTER, B. In vitro of Petasites hybridus (Asteraceae) from leaf and petiole explants and from inflorescence buds. Plant Cell Reports, New York, v. 18, n. 3/4, p. 336-340, Dec. 1998. 